\title{
Frankincense, pine needle and geranium essential oils suppress tumor progression through the regulation of the AMPK/mTOR pathway in breast cancer
}

\author{
PENG REN ${ }^{1}$, XIANG REN $^{2}$, LEI CHENG $^{1}$ and LIXIN XU ${ }^{1}$ \\ ${ }^{1}$ The First Affiliated Hospital of Dalian Medical University; ${ }^{2}$ College of Stomatology, Dalian Medical University, \\ Dalian, Liaoning 116044, P.R. China
}

Received April 25, 2017; Accepted October 13, 2017

DOI: $10.3892 /$ or.2017.6067

\begin{abstract}
BC (BC), as the most common malignancy in women worldwide, is associated with high morbidity and mortality. However, chemoresistance and toxicity are the main causes that limit the success of treatment in aggressive BC cases. Thus, there is a vital need to identify and develop novel therapeutic agents. Frankincense, pine needle and geranium essential oils have been reported to play critical biological activities in cancer. However, to the best of our knowledge whether frankincense, pine needle and geranium essential oils have any effect on the progression of BC in MCF-7 cells remains unclear. In the present study, we assessed the possible effects of frankincense, pine needle and geranium essential oils on cell viability, proliferation, migration and invasion as well as the possible mechanisms. MCF-7 cells were treated with oils, and associations with $\mathrm{BC}$ were investigated. In the present study, we clearly revealed that frankincense, pine needle and geranium essential oils suppressed cell viability, proliferation, migration and invasion in human $\mathrm{BC} \mathrm{MCF}-7$ cells. Further data demonstrated that frankincense, pine needle and geranium essential oils induced apoptosis, but did not affect cell cycle progression. Consistent with the in vitro activities, frankincense essential oil was effective in inhibiting tumor growth and inducing tumor cell apoptosis in a human $\mathrm{BC}$ mouse model. In addition, these 3 essential oils modulated the activity of the AMPK/mTOR signaling pathway.
\end{abstract}

Correspondence to: Dr Lixin Xu or Lei Cheng, The First Affiliated Hospital of Dalian Medical University, Dalian, Liaoning 116044, P.R. China

E-mail: xulixin99@sina.com

E-mail: docchenglei@163.com

Abbreviations: $\mathrm{BC}$, breast cancer; PTX, paclitaxel; TUNEL, transferase-mediated deoxyuridine triphosphate-biotin nick end labeling; PARP, poly(ADP-ribose) polymerase; RPMI, Roswell Park Memorial Institute; WT, cells treated with nothing; PBS, phosphate-buffered saline; SDS, sodium dodecyl sulfate

Key words: breast cancer, essential oils, progression, AMPK/mTOR
In conclusion, the present study indicated that frankincense, pine needle and geranium essential oils were involved in the progression of BC cells possibly through the AMPK/mTOR pathway.

\section{Introduction}

$\mathrm{BC}(\mathrm{BC})$ is the most common malignant disease among women worldwide, and is associated with high morbidity and mortality (1). Surgery combined with adjuvant therapy was the main treatment strategy in BC patients. In addition, endocrine and targeted therapies were gradually applied to clinical therapy $(2,3)$. However, in the treatment of aggressive $\mathrm{BC}$ cases, chemoresistance and toxicity are the leading causes for failure. Thus, it is important to define and develop new therapeutic agents, which may bind to BC cells specifically and effectively.

Frankincense, the gum resin derived from Boswellia species, contains active ingredients. The oil has been demonstrated to modulate critical biological activities including anti-rheumatism, anti-inflammatory $(4,5)$, antibacterial, antifungal and anticancer activities (6-9). Frankincense oil is prepared by the steam distillation of frankincense gum resin. Based on the biological function of frankincense, it possibly possesses anticancer characteristics. Pine needle (Pinus densiflora Siebold \& Zucc.), is usually utilized as a herbal medicine, tea bag infusion and health supplement in East Asian countries, such as Korea and China (10). It is beneficial in the therapy of patients with coronary heart disease (CHD), neurodegenerative disorders and carcinoma. Moreover, it was also reported that extracts from pine needle inhibited apoptosis of the normal cells induced by a hydroxyl radical (11). As a central material, geranium essential oil has been used in the cosmetic, perfume, aromatherapy and food industries. In addition, the oil famous for its antibacterial, antioxidative and anti-inflammatory properties, has been used as a traditional drug for a long time (12-15).

However, whether frankincense, pine needle and geranium essential oils have any effect on progression of BC in MCF-7 cells remains unclear. The present study investigated the anticancer properties of the prepared essential oils on the MCF-7 cells. Moreover, we elucidated the regulatory AMPK/mTOR 
pathway involving essential oils in BC cell proliferation, invasion and apoptosis development.

\section{Materials and methods}

Cell culture. MCF-7 cells were obtained from the Dalian Institute of Chemical Physics, Chinese Academy of Sciences (Dalian, China). Cells were seeded in RPMI-1640 medium (HyClone, Logan, UT, USA) supplemented with $10 \%$ fetal bovine serum (FBS; Gibco, Grand Island, NY, USA) and 1\% penicillin-streptomycin (Invitrogen, Carlsbad, CA, USA). The cells were maintained in a humidified incubator at $37^{\circ} \mathrm{C}$ with $5 \% \mathrm{CO}_{2}$.

Materials. Stock solutions of frankincense, pine needle and geranium essential oils were obtained from the Hualin Natural Health Cosmetics Company (Beijing, China). Dimethyl sulfoxide (DMSO) at a ratio of 1:2 (v/v) was used as a vehicle of the oils. Subsequently, the oils were diluted with complete medium to a series of different concentrations. The frankincense injection was prepared by diluting the stock solution of frankincense by mixing it with DMSO in a 1:2 ratio, and then diluting this mixture to $1: 1,000(\mathrm{v} / \mathrm{v})$ with phosphate-buffered saline (PBS). The frankincense smear was prepared by diluting the stock solution of frankincense to $1 \%(\mathrm{v} / \mathrm{v})$ with grape seed oil.

Western blotting. SDS buffer $(60 \mathrm{mM}$ Tris- $\mathrm{HCl}$ with a $\mathrm{pH}$ value at $6.8,10 \%$ glycerol, $2 \%$ SDS, with 5\% 2-mercaptoethanol) was utilized to store the lysate of the cells and tissues. The 4-12\% sodium dodecyl sulfate-polyacrylamide gel electrophoresis (SDS-PAGE) gels were used to separate the cell lysate. Proteins were transferred to polyvinylidene fluoride (PVDF) membranes (Invitrogen), and the membranes were blocked with Tris-buffered saline plus $0.1 \%$ Tween-20 (TTBS) containing 5\% skim milk for $2 \mathrm{~h}$. The primary antibodies specific to phospho-ERK, total-ERK, phospho4E-BP1, phospho-mTOR, total-mTOR, phospho-AMPK, total-AMPK, poly(ADP-ribose) polymerase (PARP) (Asp214) (Cell Signaling Technology, Beverly, MA, USA), Bcl-2 (Abgent, Inc., San Diego, CA, USA) were immunoblotted. All bands were washed in TBS with Tween-20 (TBST) and immunoblotted with peroxidase-conjugated anti-mouse or anti-rabbit secondary antibodies, respectively. The bands were detected using an enhanced chemiluminescence (ECL) Western Blotting kit and exposed to film. The $\beta$-actin antibody (BIOSS, Beijing, China) was used as an internal marker for control. All experiments were carried out thrice.

Cell cycle analysis. For DNA content analysis, MCF-7 cells were treated with different oils. The cells were gathered, washed and resuspended after $48 \mathrm{~h}$. Ethanol (75\%) was used to fix cells overnight. The cells were centrifugated and exposed to RNase $(100 \mu \mathrm{l})$ for $30 \mathrm{~min}$ at $37^{\circ} \mathrm{C}$. Propidium iodide (PI) (400 $\mu \mathrm{l}$ ) was used to stain DNA for $30 \mathrm{~min}$ without light. DNA contents were analyzed using BD Biosciences Accuri C6 flow cytometer (BD Biosciences, Franklin Lakes, NJ, USA) and FlowJo software. DNA histograms in the G0-G1, S and $\mathrm{G} 2-\mathrm{M}$ phases were defined and the ratio in each phase was calculated.
Apoptosis assay. Cell apoptosis assays were carried out with the use of an Annexin V-FITC apoptosis detection kit. Specifically, cells $\left(1 \times 10^{5}\right.$ cells/well) were treated with or without oils for $48 \mathrm{~h}$, collected, washed and resuspended. Then, the cells were treated with a mixture of Annexin V-FITC and PI for $15 \mathrm{~min}$ in the dark at room temperature. Subsequently, binding buffer (400 $\mu \mathrm{l}$ ) was added. The cells were then analyzed by the BD Biosciences Accuri C6 flow cytometer.

Cell Counting Kit-8 (CCK-8) assay. To evaluate cell proliferation, cells $\left(1 \times 10^{5}\right.$ cells/well) were plated in 96-well plates containing $100 \mu \mathrm{l}$ full medium, and incubated with different oils at various time-points. CCK-8 (10 $\mu \mathrm{l})$ was added to the plates and incubation followed at $37^{\circ} \mathrm{C}$ in $5 \% \mathrm{CO}_{2}$ for $4 \mathrm{~h}$. The spectrometric absorbance was determined by microplate spectrophotometer (Multiscan MK3; Thermo Fisher Scientific, Waltham, MA, USA) at $450 \mathrm{~nm}$.

Focus formation assay. Cells $\left(5 \times 10^{2}\right.$ cells/well) were trypsinized to a single-cell suspension and seeded into 6-well plates. The cultures were plated in the corresponding media with different oils until the appearance of foci from transformed cells was evident (8 days after incubation). Crystal violet (0.2\%) was utilized to stain the colonies and images were captured with a Nikon digital camera (Nikon Corporation, Tokyo, Japan).

Wound healing assay. Wound healing assay was performed to evaluate the migratory ability of the tumor cells. Briefly, MCF-7 $\left(1 \times 10^{4}\right)$ cells were cultured into a 12 -well plate with various oil treatments and increased to $70-80 \%$ confluence. The sterilized P200 pipette tip passed through the cell monolayer causing a wound. The cells were observed to migrate to the wound at different times. The migrated cells to the injured area were photographed at different time-points under an inverted microscope. In each well, at least 8 regions of each condition were captured randomly at a magnification of $\mathrm{x} 100$. The experiment was conducted in triplicate.

Cell invasion assay. A cell invasion assay was performed using Transwell inserts with polycarbonate membranes of 8.0- $\mu \mathrm{m}$ pore size (Corning Inc., Corning, NY, USA) with ECMatrix gel (Chemicon, Temecula, CA, USA) to form a continuous thin layer. In brief, $4 \times 10^{4}$ cells (with different oil treatments) and serum-free medium were inoculated into the upper chamber. Culture medium containing 10\% FBS was used as a chemical attractant in the lower chamber. Cells were incubated at $37^{\circ} \mathrm{C}$ in incubators for $24 \mathrm{~h}$. Then, the invaded cells under the membrane were fixed with methanol, stained with Wright-Giemsa, photographed (magnification, x400) and cells were counted in 5 random areas. Each experiment was performed thrice.

In vivo assays for tumor growth. To further determine whether frankincense regulated tumor growth, in vivo tumorigenesis was performed. MCF-7 cells $\left(2 \times 10^{5}\right)$ were injected into the left and right dorsal flank of 4-5 week-old female nude mice (purchased from the Animal Center Dalian Medical University), respectively. When mice exhibited a palpable tumor $(\sim 1$ week after tumor cell inoculation), they were randomly divided into 7 groups ( $n=5$ animals/group): the WT 

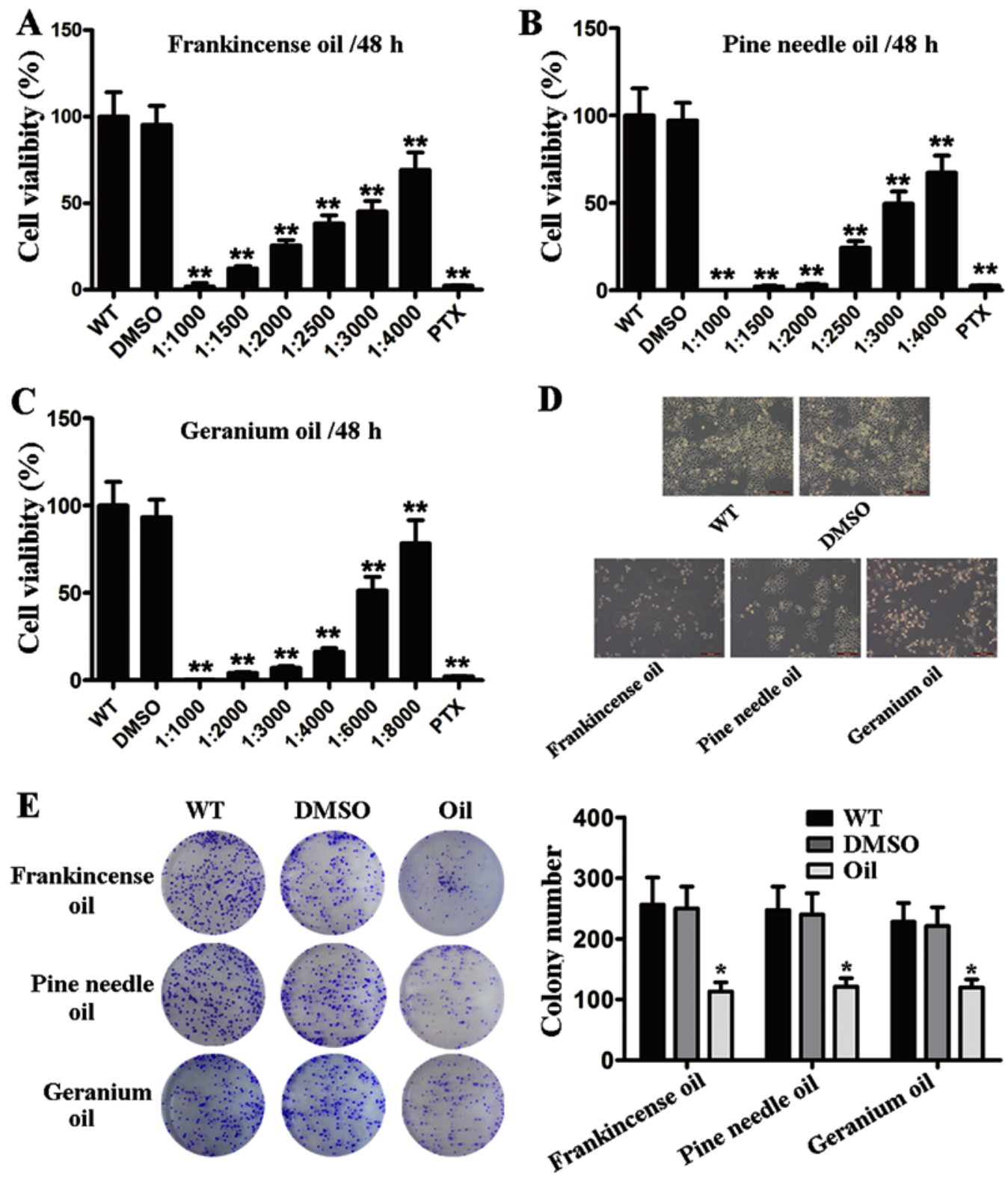

Figure 1. Frankincense, pine needle and geranium essential oils suppress the cell viability and proliferation of MCF-7 cells. (A-C) MCF-7 cells were seeded in a 96-well tissue culture. The cells were subjected to serial dilutions of frankincense, pine needle and geranium essential oils treatment (WT, cells treated with nothing; DMSO, cells treated with DMSO; oil, cells treated with oil; PTX, cells treated with paclitaxel). Cell viability was determined at $48 \mathrm{~h}$ after essential oil treatment by CCK-8 assay. (D) Morphological changes of MCF-7 cells following frankincense, pine needle and geranium essential oil stimulation. MCF-7 cells were subjected to frankincense, pine needle and geranium essential oil, respectively $(1: 3,000 ; 1: 3,300 ;$ and 1:6,000 v/v). Images were captured at $48 \mathrm{~h}$ after treatment. (E) Cells were seeded in each well of a 6-well plate, subsequently exposed to and incubated with frankincense/pine needle/geranium essential oil $(1: 3,000 ; 1: 3,300$; and 1:6,000 v/v). After 8 days of culture, the surviving colonies were counted with crystal violet staining. Data are presented as the mean \pm SD from 3 independent experiments $\left({ }^{*} \mathrm{P}<0.05,{ }^{* *} \mathrm{P}<0.01\right)$.

group, treated with nothing; the DMSO and negative group, treated with DMSO subcutaneous injection; the base oil and negative group, treated with grape seed oil smear; the injection group, treated with frankincense subcutaneous injection $(1: 1,000 \mathrm{v} / \mathrm{v}, 0.1 \mathrm{ml})$; the external smear group, treated with frankincense smear $(0.1 \mathrm{ml})$; the combination group, treated with frankincense subcutaneous injection combined with frankincense smear; the PTX and positive group, treated with PTX subcutaneous injection (10 mg/kg) (16). The treatment was administered every 4 days for 12 days. The tumor dimensions were gauged every 4 days for 12 days (17). The estimated tumor volume $\left(\mathrm{mm}^{3}\right)$ was calculated using the following formulas: Tumor volume $=$ length $\mathrm{x}$ width ${ }^{2} \mathrm{x} 0.52$.
All mice were kept under specific pathogen-free conditions for air filtration. All experiments with animals complied with the standards in the guidelines of the University Animal Care and Use Committee of Dalian Medical University. Finally, the tumors were fixed in $10 \%$ formalin and embedded in paraffin for immunohistochemistry.

Tunel assay. TUNEL analysis was used to determine the apoptosis of tumor cells induced by essential oils. In short, the paraffin section was cut into $5-\mu \mathrm{m}$ of thickness, dewaxed and rehydrated. Apoptotic cells were detected using an in situ cell death assay kit. After the terminal deoxynucleotidyl transferase reaction, the labeled end of the incision was identified 
A
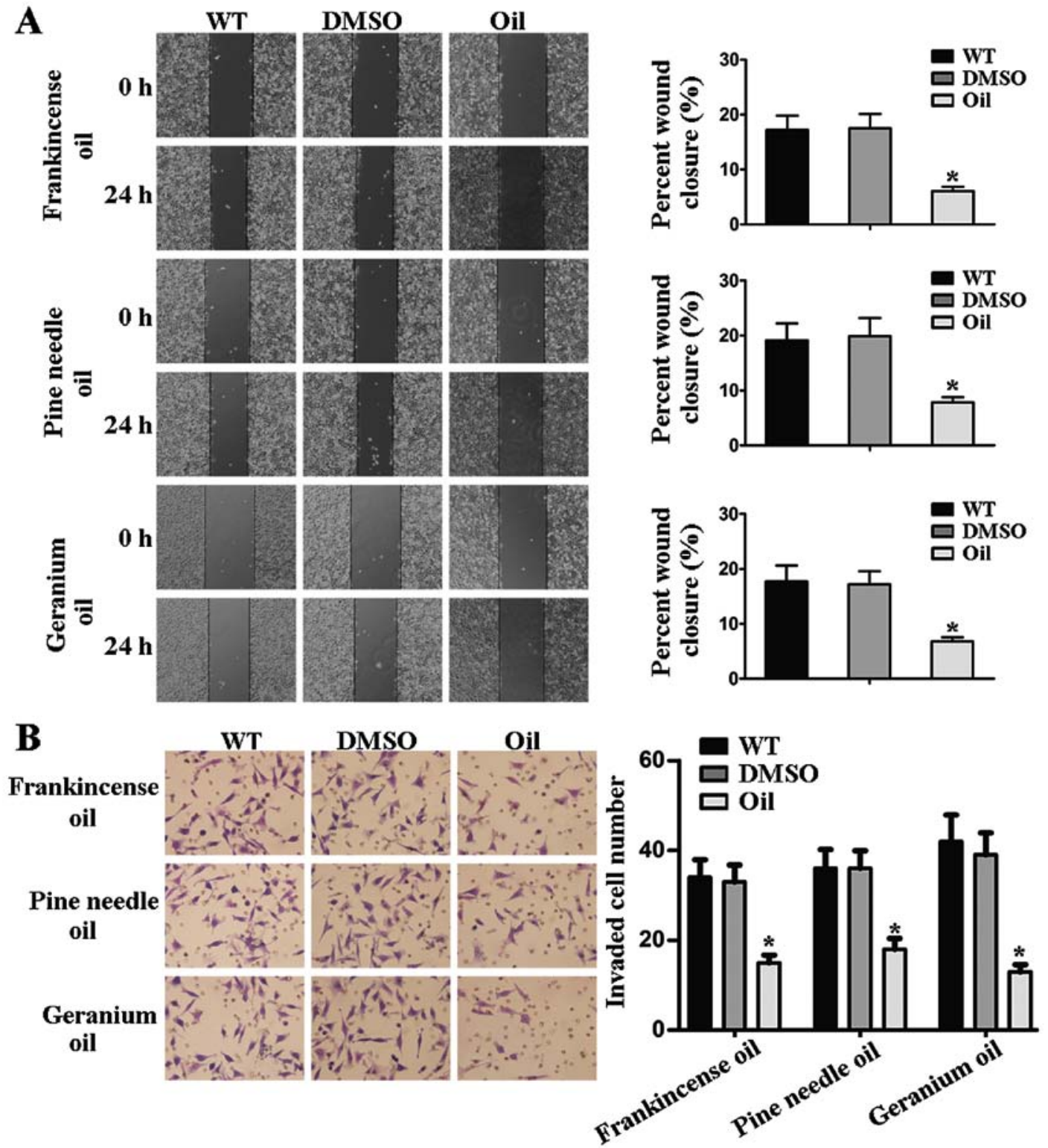

Figure 2. Frankincense, pine needle and geranium essential oils suppress the migration and invasion of MCF-7 cells. (A) The ability of migration was compared in frankincense, pine needle and geranium essential oil treatments and control groups based on wound healing ( $\left.{ }^{*}<0.05\right)$. (B) In vitro ECMatrix gel analysis was performed to compare the cell invasion between 3 essential oil-treated cells and control groups $\left({ }^{*} \mathrm{P}<0.05\right)$. Values are presented as the mean $\pm \mathrm{SD}$ from 3 independent experiments.

by alkaline phosphatase-based immunohistochemistry, with fast red as the substrate. Stained slides were washed and sealed with an aqueous mounting medium.

Statistical analysis. Student's t-test was applied to detect statistically significant differences for non-paired replicates. One-way analysis of variance (ANOVA) was used to compare replicate means. $\mathrm{P}$-value $<0.05$ was considered to indicate a statistically significant result $(\mathrm{P}<0.05, \mathrm{P}<0.01)$. Error bars represent the mean \pm standard deviation $(\mathrm{SD})$ unless specified otherwise.

\section{Results}

Frankincense, pine needle and geranium essential oils suppress MCF-7 cell viability and proliferation. To determine whether these three essential oils affected MCF-7 cell viability, the number of viable MCF-7 cells was determined following various dilutions (frankincense, 1:1,000-1:4,000; pine needle, 1:1,000-1:4,000; geranium, 1:1,000-1:8,000) of oil exposure. As shown in Fig. 1A-C, the cell viability was decreased in a dose-dependent manner when MCF-7 cells were treated with oil. In addition, no viable MCF-7 cells remained after $48 \mathrm{~h}$ treatment with 1:1,000 dilution of oil. Based on the CCK-8 assay, $\mathrm{IC}_{50}$ values (the $50 \%$ inhibitory concentration of frankincense/pine needle/geranium essential oil) for MCF-7 cells were $42.8 \mu \mathrm{g} / \mathrm{ml}, 90.2 \mu \mathrm{g} / \mathrm{ml}$ and $73.9 \mu \mathrm{g} / \mathrm{ml}$, respectively (data not shown). Moreover, to determine whether oil suppresses cell viability, MCF-7 cells were subjected to morphological evaluation assessment. As shown in Fig. 1D, MCF-7 cells underwent significant morphological changes, such as detaching from tissue culture plates and shrinking following oil exposure (with $\mathrm{IC}_{50}$ dilution treatment for $48 \mathrm{~h}$ ). Furthermore, the colony formation assay revealed that the colony size and colony 

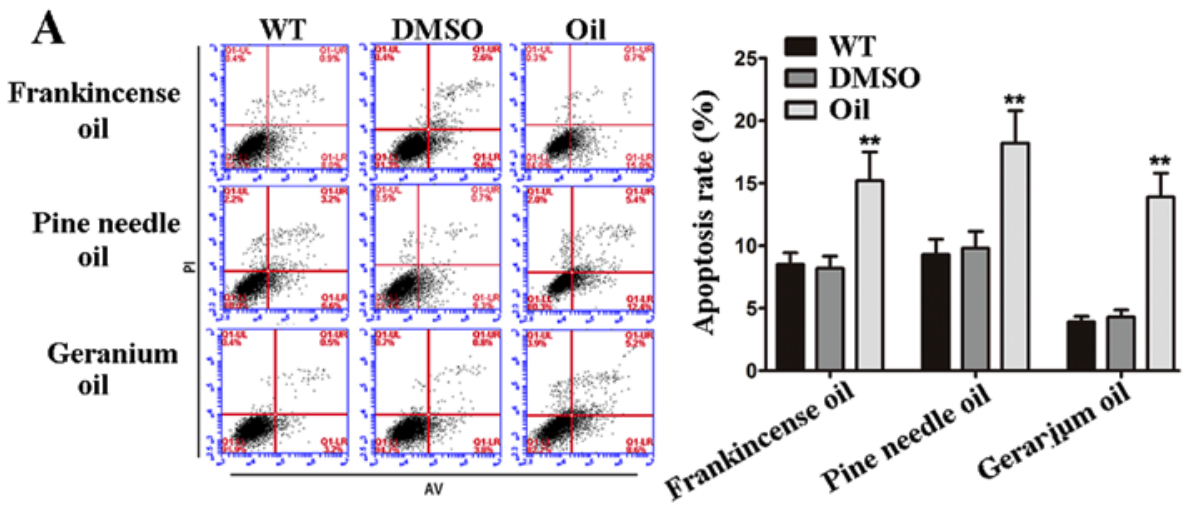

B
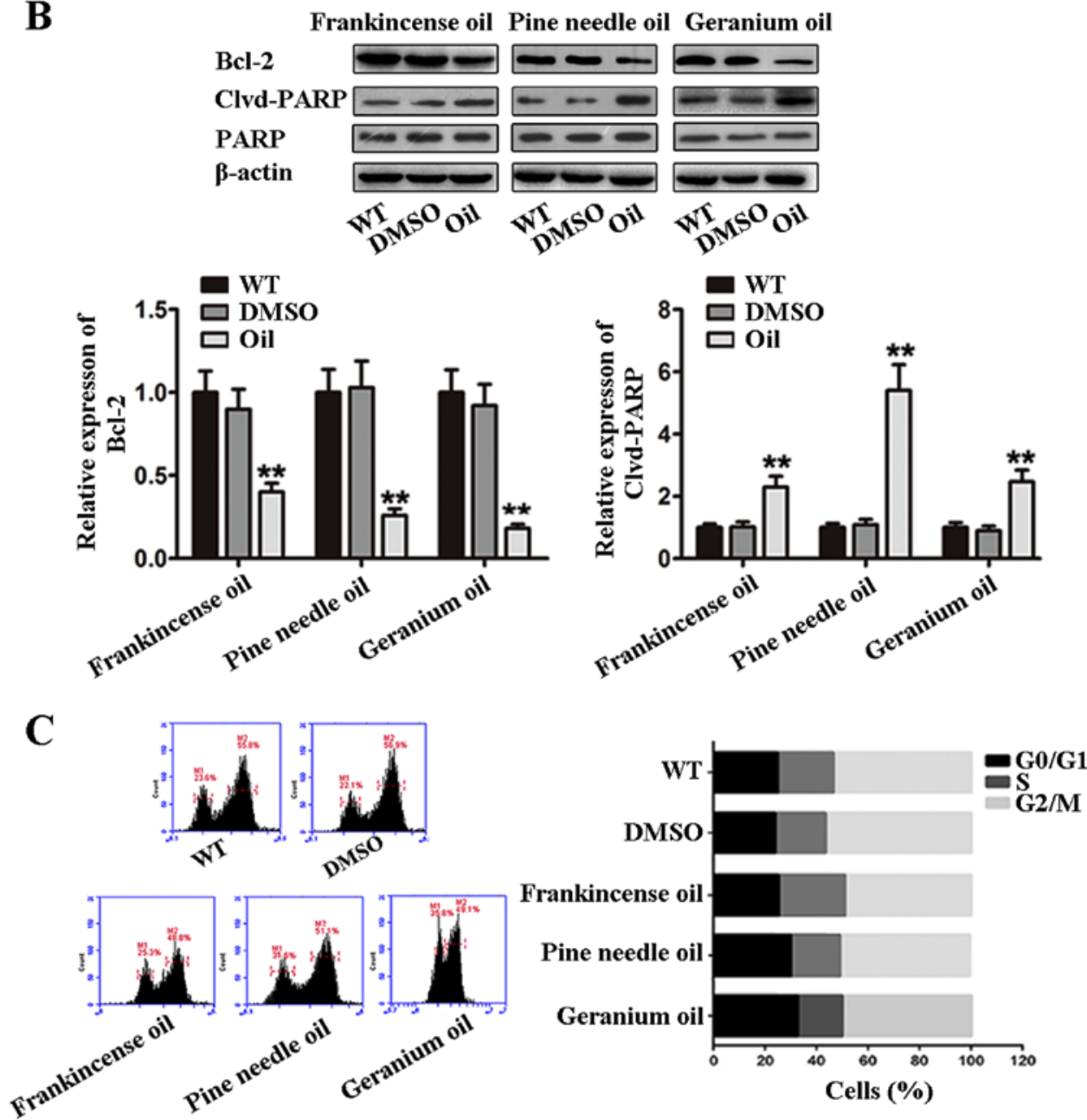

Figure 3. Frankincense, pine needle and geranium essential oils regulate apoptosis and the cell cycle of MCF-7 cells. (A) MCF-7 cells were treated with oils (frankincense, 1:3,300; pine needle, 1:3,000; geranium essential oil, 1:6,000) for $48 \mathrm{~h}$, respectively. Cell apoptosis was analyzed by flow cytometry. (B) Bcl-2 and Clvd-PARP were analyzed by western blotting in MCF-7 cells treated with 3 essential oils. (C) MCF-7 cells were treated with 3 essential oils and the cell cycle was analyzed by flow cytometry $\left({ }^{* *} \mathrm{P}<0.01\right)$.

forming capacity of MCF-7 cells were strongly reduced in the presence of the oils compared to the controls (Fig. 1E). These results indicated that frankincense, pine needle and geranium essential oils played a role in BC cell proliferation.

Frankincense, pine needle and geranium essential oils regulate aggressiveness of $M C F-7$ cells. To examine whether these 3 essential oils exerted a direct regulation on the response to $\mathrm{BC}$ aggressiveness, $\mathrm{MCF}-7$ cells were treated with different essential oils. Upon frankincense, pine needle and geranium essential oil treatments, the migratory capability was significantly decreased as determined by wound healing assay (Fig. 2A). Concomitantly to the aforementioned experiments, we investigated the potential role of these 3 essential oils in mediating the invasive abilities of MCF-7 cells. The results of the Transwell invasion assay revealed that the invaded cell number/field was much lower than that in the control group (Fig. 2B). Collectively, these results demonstrated that frankincense, pine needle and geranium essential oils regulated the aggressiveness of $\mathrm{BC}$ cells. 
A

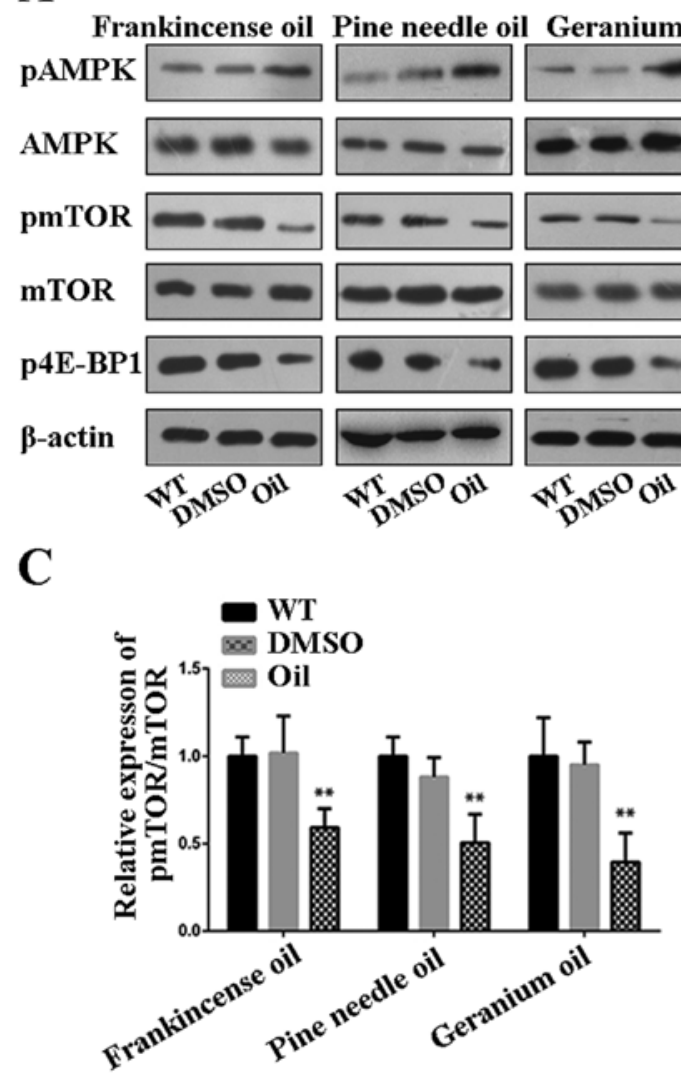

B

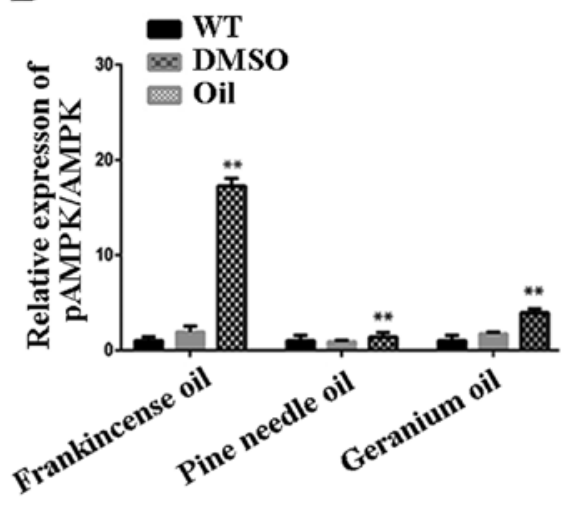

D

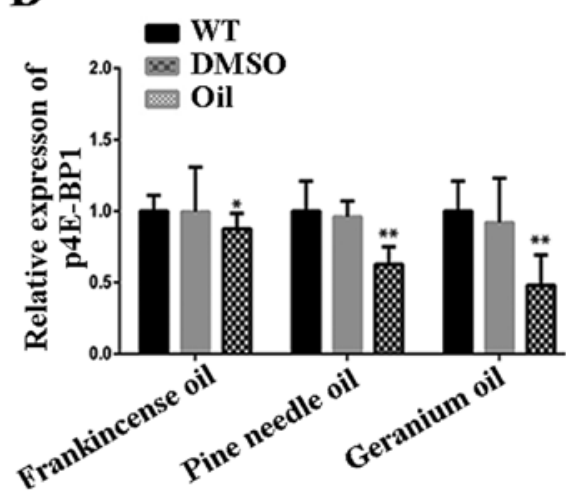

Figure 4. Effect of frankincense, pine needle and geranium essential oil-activated AMPK/mTOR signaling pathway. (A) MCF-7 cells were exposed to oils (frankincense, 1:3,300; pine needle, 1:3,000; geranium essential oil, 1:6,000). The expression of AMPK/mTOR signaling molecules was suppressed at the protein levels with these 3 essential oil treatments in MCF-7 cells. Frankincense, pine needle and geranium essential oils markedly increased the phosphorylation of AMPK and decreased the phosphorylation of mTOR. The blots were probed for $\beta$-actin as a loading control. (B-D) The relative expression of AMPK/mTOR signaling molecules was determined in MCF-7 cells $\left({ }^{*} \mathrm{P}<0.05,{ }^{* *} \mathrm{P}<0.01\right)$.

Frankincense, pine needle and geranium essential oils regulate apoptosis and the cell cycle of MCF-7 cells. To explore the potential role of these 3 essential oils in modulating the apoptosis and cell cycle, MCF-7 cells were treated with oils (frankincense, 1:3,300; pine needle, 1:3,000; geranium essential oil, 1:6,000) for $48 \mathrm{~h}$, respectively. Cell apoptosis and the cell cycle were analyzed by flow cytometry. As shown in Fig. 3A, the number of apoptotic cells was increased in groups treated with the oils, compared with the WT and DMSO control groups. Cleavage of PARP was involved in DNA repair following environmental stress (18). We also detected the expression of cleaved PARP to evaluate the apoptotic activity of MCF-7 cells treated with the oils. Cleaved PARP levels were increased in the oil-treated cells (Fig. 3B). We also determined the expression of the Bcl-2 protein, and found that the oils induced a decrease in the expression of Bcl-2. Furthermore, we analyzed the cell cycle of MCF-7 cells and found that the percentage of cells arrested at the G0/G1, S and G2-M phases were not significantly altered (Fig. 3C). Collectively, these results indicated that frankincense, pine needle and geranium essential oils induced apoptosis but not cell cycle arrest of MCF-7 cells.

Frankincense, pine needle and geranium essential oils mediate the activity of the AMPK/mTOR pathway. AMPK activation has been demonstrated to regulate key proliferative signaling events such as mTOR/p70S6K (19). In addition, mTOR was demonstrated to be a central controller of cell proliferation, growth and survival (20). In the present study, we assessed the activity of the AMPK signaling and its downstream target by treatment of MCF-7 cells with frankincense, pine needle and geranium essential oils. Western blot analysis revealed that the levels of phosphorylated-AMPK were increased in MCF-7 cells treated with these 3 essential oils (Fig. 4A and B). Concomitantly, the degrees of phosphorylation of mTOR and its downstream effector 4E-BP1 were markedly decreased in MCF-7 cells treated with these 3 essential oils. Conversely, there was no change in the total amount of AMPK and mTOR protein, demonstrating a true decrease in phosphorylation status. These results revealed that the antiproliferative, antiinvasive and induced-apoptosis effect of frankincense, pine needle and geranium essential oils on MCF-7 cells involved AMPK-initiated mTOR inhibition.

Frankincense essential oil modulates tumor growth in a xenograft mouse model. Finally, we examined the tumorigenesis of frankincense essential oil in MCF-7 cells by in vivo experiments. Administration with frankincense subcutaneous injection, frankincense smear, frankincense subcutaneous injection combined with frankincense smear significantly suppressed tumor growth in nude mice implanted with established MCF-7 tumors (Fig. 5A). Moreover, the tumor growth 


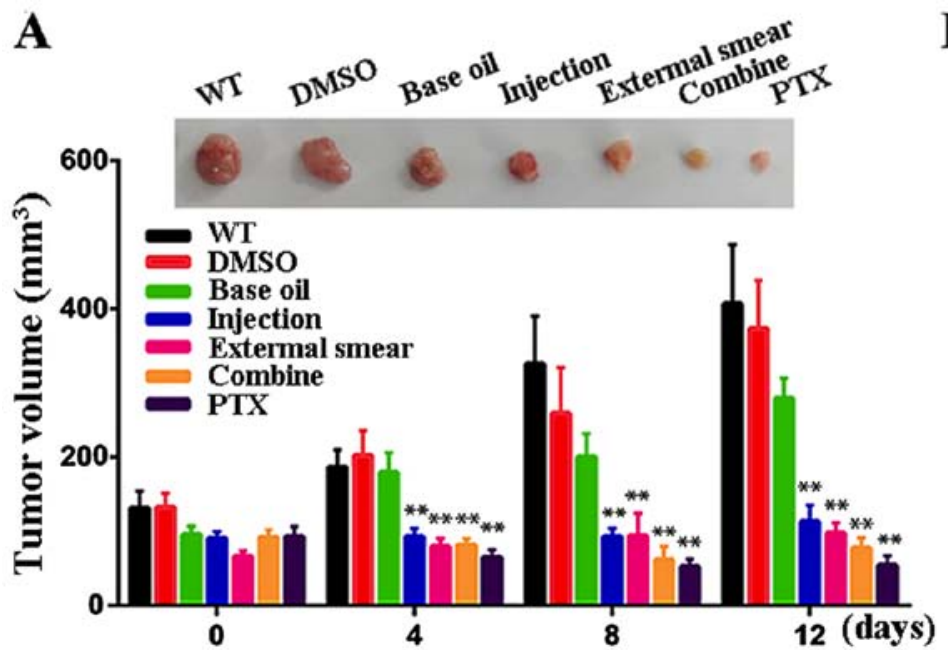

B

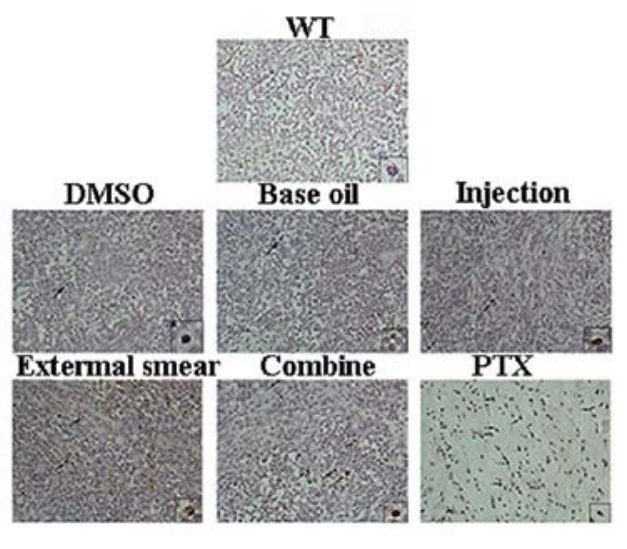

Figure 5. Frankincense essential oil regulates tumor growth in a xenograft mouse model. (A) MCF-7 cells were implanted into the left and right flanks of nude mice respectively $(n=6)$. One week later, the mice were randomly divided into 7 groups, followed treatment as described in the Materials and methods section. The tumor volumes are shown as indicated. (B) The apoptosis in tumor were detected by TUNEL assay $\left({ }^{*} \mathrm{P}<0.05,{ }^{* *} \mathrm{P}<0.01\right)$.

rate of the combined group was slowler than that of the injection group and the smear group. Furthermore, TUNEL assay revealed a significantly higher number of TUNEL-positive cells that were detected in the experimental group, compared with the control group. In addition, the results demonstrated that the number of apoptotic cells in combination group was higher than that in the other experimental control groups (Fig. 5B). Collectively, in vivo studies confirmed that frankincense suppressed tumor growth and induced apoptosis.

\section{Discussion}

In the present study, we clearly demonstrated that frankincense, pine needle and geranium essential oils suppressed cell viability, proliferation and invasion in human BC cell line MCF-7. In addition, we determined that the frankincense, pine needle and geranium essential oils induced apoptosis, but did not affect cell cycle progression. The frankincense essential oil was also effective in inhibiting tumor growth and inducing tumor cell apoptosis in human BC mouse model. We demonstrated that frankincense, pine needle and geranium essential oils suppressed cell progression through the AMPK/mTOR pathway.

Essential oils, which are distilled from flowers, leaves, stems, the bark or roots of a specific plant, contained terpenes, aldehydes, esters, alcohols and other chemical molecules. It has been demonstrated that essential oils have an antibacterial and anti-inflammatory effect. Moreover, research has reported that essential oils also have a certain anticancer effect. Wu et al demonstrated that essential oils from Angelicae dahuricae and Inula japonica increased the sensitivity of BC cell line MCF-7/ADR to doxorubicin (21). Essential oils distilled from the leaves and flowers of Callistemon citrinus from the western Himalayas gave rise to the antiproliferative effect on human lung carcinoma cell line A549 and rat glioma C-6 cells via induction of apoptosis (22). Thymoquinone decreased proliferation and accelerated apoptosis in ID8-NGL (mouse ovarian cancer cells) tumors after 10 and 30 day-treatment (23). It has been observed thymoquinone mediated cell cycle arrest and apoptosis in BC and hepatocellular carcinoma $(24,25)$. Boswellic acids (major components of frankincense) were reported to possess antitumor activity due to their cytostatic and pro-apoptotic properties in many human cancer cell lines containing meningioma (26), leukemia (27), hepatocellular carcinoma (28), melanoma, fibrosarcoma (29), colon (30) and prostate cancer (31-33). Moreover, the essential oil of frankincense inhibited proliferation and modulated apoptosis of human cancer cell lines both in vitro and in vivo $(17,34,35)$. According to a study by Jeong et al, apoptosis, oxidative cell damage, induced by exposure to hydroxyl radical was inhibited by the extracts from pine needle (11). In the present study, we demonstrated that frankincense, pine needle and geranium essential oils reduced MCF-7 cell viability in a dose-dependent manner. Moreover, frankincense, pine needle and geranium essential oils strongly reduced colony size and colony forming capacity of MCF-7 cells. The treatment of frankincense, pine needle and geranium essential oils was responsible for the altered migratory and invasive phenotype of MCF-7 cells in vitro. Our results further indicated that the frankincense, pine needle and geranium essential oils induced apoptosis. However, the oils did not affect cell cycle progression. Furthermore, we observed that the essential oil of frankincense inhibited tumor growth and induced apoptosis in vivo. These results clearly revealed that frankincense, pine needle and geranium essential oils could play an important role in many biological functions of $\mathrm{BC}$ cells such as proliferation, invasion as well as apoptosis.

Further analysis of molecular mechanisms for cancer cell progression may provide more data concerning novel molecular targets of frankincense, pine needle and geranium essential oil treatments for BC. AMPK is a central cellular energy-sensing system that constructively takes part in the interaction between metabolism and cancer progression by regulation of the mTOR pathway (36). The activation of AMPK directly phosphorylates and activates TSC2 by increasing its GAP activity and inhibiting mTOR signaling (37). The serine/threonine kinase mammalian target of rapamycin (mTOR) functions as a major regulator of cellular growth and survival, and resides in two multiprotein complexes, mTORC1 and mTORC2 (38). 
mTORC1 regulates phosphorylation of p70 S6 kinase 1 (S6K1) and eukaryotic initiation factor $4 \mathrm{E}$ (eIF4E) binding protein 1 (4EBP1) $(20,39)$. It was reported that aspirin decreased the viability and anchorage-independent growth of mutant PIK3CA BC cells through AMP-activated protein kinase (AMPK) activation and mTORC1 inhibition (40). Furthermore, in BC, 17- $\beta$-oestradiol (E2) directly activated AMPK through interaction of its $\alpha$-subunit with estrogen receptors, implying its roles in cell proliferation (41). Knockdown of AMPK inhibited glucose metabolism and proliferation of TNBC cells (42). Based on the aforementioned, we analyzed the correlation of the frankincense, pine needle and geranium essential oilsmediated AMPK and mTOR signaling pathway. We revealed that these 3 essential oils notably regulated the activity of the AMPK/mTOR pathway in human BC cells MCF-7. These results demonstrated that frankincense, pine needle and geranium essential oil-modulated $\mathrm{BC}$ cell progression was, at least in part, AMPK/mTOR-dependent.

In conclusion, our results demonstrated that frankincense, pine needle and geranium essential oils have an antitumor effect, which could be mediated by the AMPK/mTOR pathway. The novelty of the present study was that the frankincense, pine needle and geranium essential oils may be a promising treatment for BC. However, the present study still had some shortcomings. To further confirm our present findings, similar experiments using the other $\mathrm{BC}$ cell lines should be performed. In addition, it is unclear whether the oils have an effect on BC patients. Thus, further investigation is warranted to analyze the effects and accurate mechanisms of frankincense, pine needle and geranium essential oils in BC.

\section{References}

1. Rahimi Z, Yari K and Rahimi Z: Matrix metalloproteinase-9 -1562T allele and its combination with MMP-2 -735 C allele are risk factors for BC. Asian Pac J Cancer Prev 16: $1175-1179,2015$

2. Fox P, Balleine RL, Lee C, Gao B, Balakrishnar B, Menzies AM, Yeap SH, Ali SS, Gebski V, Provan P, et al: Dose escalation of tamoxifen in patients with low endoxifen level: Evidence for therapeutic drug monitoring - The TADE study. Clin Cancer Res 22: 3164-3171, 2016.

3. Sabol M, Trnski D, Uzarevic Z, Ozretic P, Musani V, Rafaj M, Cindric $M$ and Levanat $S$ : Combination of cyclopamine and tamoxifen promotes survival and migration of mef-7 BC cells - interaction of hedgehog-gli and estrogen receptor signaling pathways. PLoS One 9: e114510, 2014.

4. Poeckel D and Werz O: Boswellic acids: Biological actions and molecular targets. Curr Med Chem 13: 3359-3369, 2006.

5. Ammon HP: Boswellic acids in chronic inflammatory diseases. Planta Med 72: 1100-1116, 2006.

6. Syrovets T, Büchele B, Krauss C, Laumonnier Y and Simmet T: Acetyl-boswellic acids inhibit lipopolysaccharide-mediated TNF-alpha induction in monocytes by direct interaction with IkappaB kinases. J Immunol 174: 498-506, 2005.

7. Büchele B and Simmet T: Analysis of 12 different pentacyclic triterpenic acids from frankincense in human plasma by high-performance liquid chromatography and photodiode array detection. J Chromatogr B Analyt Technol Biomed Life Sci 795: 355-362, 2003.

8. Siemoneit U, Pergola C, Jazzar B, Northoff H, Skarke C, Jauch J and Werz O: On the interference of boswellic acids with 5-lipoxygenase: Mechanistic studies in vitro and pharmacological relevance. Eur J Pharmacol 606: 246-254, 2009.

9. Burdine L and Kodadek T: Target identification in chemical genetics: The (often) missing link. Chem Biol 11: 593-597, 2004.

10. Kwak CS, Moon SC and Lee MS: Antioxidant, antimutagenic, and antitumor effects of pine needles (Pinus densiflora). Nutr Cancer 56: 162-171, 2006.
11. Jeong JB, Seo EW and Jeong HJ: Effect of extracts from pine needle against oxidative DNA damage and apoptosis induced by hydroxyl radical via antioxidant activity. Food Chem Toxicol 47: 2135-2141, 2009.

12. Lis-Balchin M and Deans SG: Antimicrobial effects of hydrophilic extracts of Pelargonium species (Geraniaceae). Lett Appl Microbiol 23: 205-207, 1996.

13. Ben Slima A, Ali MB, Barkallah M, Traore AI, Boudawara T, Allouche $\mathrm{N}$ and Gdoura R: Antioxidant properties of Pelargonium graveolens L'Her essential oil on the reproductive damage induced by deltamethrin in mice as compared to alphatocopherol. Lipids Health Dis 12: 30, 2013.

14. Boukhatem MN, Kameli A, Ferhat MA, Saidi F and Mekarnia M: Rose geranium essential oil as a source of new and safe antiinflammatory drugs. Libyan J Med 8: 22520, 2013.

15. Shim JU, Oh PS and Lim KT: Anti-inflammatory activity of ethanol extract from Geranium sibiricum Linne. J Ethnopharmacol 126: 90-95, 2009.

16. Singla AK, Bondareva A and Jirik FR: Combined treatment with paclitaxel and suramin prevents the development of metastasis by inhibiting metastatic colonization of circulating tumor cells. Clin Exp Metastasis 31: 705-714, 2014.

17. Ni X, Suhail MM, Yang Q, Cao A, Fung KM, Postier RG, Woolley C, Young G, Zhang J and Lin HK: Frankincense essential oil prepared from hydrodistillation of Boswellia sacra gum resins induces human pancreatic cancer cell death in cultures and in a xenograft murine model. BMC Complement Altern Med 12: 253, 2012.

18. Satoh MS and Lindahl T: Role of poly(ADP-ribose) formation in DNA repair. Nature 356: 356-358, 1992.

19. Kim EJ, Choi YK, Han YH, Kim HJ, Lee IK and Lee MO: RORa suppresses proliferation of vascular smooth muscle cells through activation of AMP-activated protein kinase. Int J Cardiol 175: 515-521, 2014.

20. Laplante M and Sabatini DM: mTOR signaling in growth control and disease. Cell 149: 274-293, 2012.

21. Wu M, Li T, Chen L, Peng S, Liao W, Bai R, Zhao X, Yang H, Wu C, Zeng $\mathrm{H}$, et al: Essential oils from Inula japonica and Angelicae dahuricae enhance sensitivity of MCF-7/ADR BC cells to doxorubicin via multiple mechanisms. J Ethnopharmacol 180: 18-27, 2016.

22. Kumar D, Sukapaka M, Babu GD and Padwad Y: Chemical composition and in vitro cytotoxicity of essential oils from leaves and flowers of Callistemon citrinus from western Himalayas. PLoS One 10: e0133823, 2015.

23. Wilson AJ, Saskowski J, Barham W, Khabele D and Yull F: Microenvironmental effects limit efficacy of thymoquinone treatment in a mouse model of ovarian cancer. Mol Cancer 14: $192,2015$.

24. Parbin S, Shilpi A, Kar S, Pradhan N, Sengupta D, Deb M, Rath SK and Patra SK: Insights into the molecular interactions of thymoquinone with histone deacetylase: Evaluation of the therapeutic intervention potential against BC. Mol Biosyst 12: 48-58, 2016.

25. Ke X, Zhao Y, Lu X, Wang Z, Liu Y, Ren M, Lu G, Zhang D, Sun Z, Xu Z, et al: TQ inhibits hepatocellular carcinoma growth in vitro and in vivo via repression of Notch signaling. Oncotarget 6: 32610-32621, 2015.

26. Park YS, Lee JH, Bondar J, Harwalkar JA, Safayhi H and Golubic M: Cytotoxic action of acetyl-11-keto-beta-boswellic acid (AKBA) on meningioma cells. Planta Med 68: 397-401, 2002.

27. Shao Y, Ho CT, Chin CK, Badmaev V, Ma W and Huang MT: Inhibitory activity of boswellic acids from Boswellia serrata against human leukemia HL-60 cells in culture. Planta Med 64: 328-331, 1998.

28. Liu JJ, Nilsson A, Oredsson S, Badmaev V and Duan RD: Keto- and acetyl-keto-boswellic acids inhibit proliferation and induce apoptosis in Hep G2 cells via a caspase-8 dependent pathway. Int J Mol Med 10: 501-505, 2002.

29. Zhao W, Entschladen F, Liu H, Niggemann B, Fang Q, Zaenker KS and Han R: Boswellic acid acetate induces differentiation and apoptosis in highly metastatic melanoma and fibrosarcoma cells. Cancer Detect Prev 27: 67-75, 2003.

30. Liu JJ, Nilsson A, Oredsson S, Badmaev V, Zhao WZ and Duan RD: Boswellic acids trigger apoptosis via a pathway dependent on caspase- 8 activation but independent on Fas/Fas ligand interaction in colon cancer HT-29 cells. Carcinogenesis 23: 2087-2093, 2002. 
31. Pang X, Yi Z, Zhang X, Sung B, Qu W, Lian X, Aggarwal BB and Liu M: Acetyl-11-keto-beta-boswellic acid inhibits prostate tumor growth by suppressing vascular endothelial growth factor receptor 2-mediated angiogenesis. Cancer Res 69: 5893-5900, 2009.

32. Lu M, Xia L, Hua H and Jing Y: Acetyl-keto-beta-boswellic acid induces apoptosis through a death receptor 5-mediated pathway in prostate cancer cells. Cancer Res 68: 1180-1186, 2008

33. Syrovets T, Gschwend JE, Büchele B, Laumonnier Y, Zugmaier W, Genze F and Simmet T: Inhibition of IkappaB kinase activity by acetyl-boswellic acids promotes apoptosis in androgen-independent PC-3 prostate cancer cells in vitro and in vivo. J Biol Chem 280: 6170-6180, 2005.

34. Frank MB, Yang Q, Osban J, Azzarello JT, Saban MR, Saban R, Ashley RA, Welter JC, Fung KM and Lin HK: Frankincense oil derived from Boswellia carteri induces tumor cell specific cytotoxicity. BMC Complement Altern Med 9: 6, 2009.

35. Suhail MM, Wu W, Cao A, Mondalek FG, Fung KM, Shih PT, Fang YT, Woolley C, Young G and Lin HK: Boswellia sacra essential oil induces tumor cell-specific apoptosis and suppresses tumor aggressiveness in cultured human BC cells. BMC Complement Altern Med 11: 129, 2011.

36. Jin HO, Hong SE, Woo SH, Lee JH, Choe TB, Kim EK, Noh WC, Lee JK, Hong SI, Kim JI, et al: Silencing of Twistl sensitizes NSCLC cells to cisplatin via AMPK-activated mTOR inhibition. Cell Death Dis 3: e319, 2012.
37. Inoki K, Corradetti MN and Guan KL: Dysregulation of the TSC-mTOR pathway in human disease. Nat Genet 37: 19-24, 2005.

38. Dalle Pezze P, Ruf S, Sonntag AG, Langelaar-Makkinje M, Hall P, Heberle AM, Razquin Navas P, van Eunen K, Tölle RC, Schwarz JJ, et al: A systems study reveals concurrent activation of AMPK and mTOR by amino acids. Nat Commun 7: 13254, 2016.

39. Polak P and Hall MN: mTOR and the control of whole body metabolism. Curr Opin Cell Biol 21: 209-218, 2009.

40. Henry WS, Laszewski T, Tsang T, Beca F, Beck AH, McAllister SS and Toker A: Aspirin suppresses growth in PI3K-mutant BC by activating AMPK and inhibiting mTORC1 signaling. Cancer Res 77: 790-801, 2017.

41. Lipovka Y, Chen H, Vagner J, Price TJ, Tsao TS and Konhilas JP: Oestrogen receptors interact with the $\alpha$-catalytic subunit of AMP-activated protein kinase. Biosci Rep 35: e00264, 2015.

42. Liu P, Ye F, Xie X, Li X, Tang H, Li S, Huang X, Song C, Wei W and Xie X: mir-101-3p is a key regulator of tumor metabolism in triple negative BC targeting AMPK. Oncotarget 7: 35188-35198, 2016.

This work is licensed under a Creative Commons Attribution-NonCommercial-NoDerivatives 4.0 International (CC BY-NC-ND 4.0) License. 